\title{
Challenges of Games Virtualization Applied to Educational Games
}

\author{
Wilk Oliveira dos Santos ${ }^{12}$, Clovis Gomes da Silva Junior ${ }^{3}$ \\ ${ }^{1}$ Computer Institute - Federal University of Alagoas (UFAL) - Maceió, AL - Brazil \\ ${ }^{2}$ Department of Computer Science - University of Saskatchewan (U of S) - Saskatoon, SK - \\ Canada \\ ${ }^{3}$ University of Pernambuco (UPE) - Garanhuns, PE - Brazil \\ wos@ic.ufal.br, clovis.gomes@upe.br
}

\begin{abstract}
Game Virtualization is a process of digital versions creation for traditional/physical games. In education, this process aims to create digital versions for traditional/ physical educational games, keeping psychological and pedagogical concepts from traditional version, as well as associate these concepts to contemporary game design elements. In this sense, this paper presents five challenges for Game Virtualization Applied to Educational Games: (i) design of methodologies for educational games virtualization, (i.i) design of methodologies for educational game evaluation, (i.ii) recommendation of resources for Educational Games Virtualization, (ii) multidisciplinary of Educational Games Virtualization, and (iii) professional training to Educational Games Virtualization.
\end{abstract}

Resumo. Virtualização de Jogos é um processo para criação de versões digitais para jogos tradicionais/ físicos. Em educação, este processo tem o objetivo de criar versões digitais para jogos educativos tradicionais/ físicos, mantendo os princípios pedagógicos e psicopedagógicos da versão tradicional do jogo, associando estes princípios às mecânicas contemporâneas de game design. Neste sentido, este artigo apresenta cinco desafios da Virtualização de Jogos aplicada aos Jogos Educativos: (i) criação de metodologias para virtualização de jogos digitais, (i.i) criação de metodologias especificas para avaliação de jogos, (i.ii) recomendação de recursos para Virtualização de Jogos Educativos, (ii) multidisciplinaridade da Virtualização de Jogos Educativos, e (iii) formação de profissionais para Virtualização de Jogos Educativos.

\section{Introduction}

In the last decades, the international industry of game development has been increasing, becoming an important worldwide industry. According to a recent report of Entertainment Software Association (ESA 2015), only in the United States, there are approximately 155 million of players moving, in 2014, approximately $\$ 22.41$ billion 
around the word. Additionally, another interesting recent study showed that $74 \%$ of $K-8^{l}$ teachers use digital games in the classroom (Lofgren 2015), enabling a considerable growth of the Educational Games industry in the last years.

In the academic context, a series of recent studies have been done in order to investigate effects of video games in different educational aspects and context (e.g. Anderson et al. (2010), Scoresby and Shelton (2011), Silva Neto et al. (2013) and others). These studies have highlighted a series of discussions related to video games positive effects in student's learning, such as: game fullness, motivation and others; and negative effects, such as: violence, social interaction absence and extreme appreciation of "digital" (digital activities conducted using some kind of technological device), in detriment to "traditional" (traditional (physical/ manual) activities).

In this context, recent studies addressing Game Virtualization, (e.g. Santos et al. (2015) and Oliveira and Silva Junior (2015)) in order to create digital versions to traditional/physical Educational Games, aim to keep the pedagogical and psychological aspects from traditional/physical game, and associate these aspects to contemporary game design elements. Like this, recent studies have showed a series of benefits of virtualized games, as well as highlighted a series of discussions related to design, application and evaluation of Educational Games developed based in Virtualization Games.

Thus, this paper proposes a series of different challenges for Games Virtualization applied to Educational Games: (i) Design of methodologies for educational games virtualization, (i.i) design of methodologies for educational game evaluation, (i.ii) recommendation of resources for Educational Games Virtualization, (ii) multidisciplinary of educational games virtualization, and (iii) professional training to Educational Games Virtualization. These challenges and some recommendations for future works in this field are presented and discussed in this paper.

\section{Background}

This work aims to propose a series of different challenges for Games Virtualization applied to Educational Games. Following, we present the main topics addressed in this study: Educational Games and Educational Games Virtualization, as well as some related works.

\subsection{Educational Games}

Over the last 20 years, computer games have been increasingly replaced the more traditional games as leisure activities, and have had a transformational impact on how we spend our leisure time (Connolly et al. 2012). According to these authors, Educational Games provide engaging activities and it seems like that, far from waning, interest in games for leisure is still growing.

\footnotetext{
${ }^{1}$ K-8 schools are schools in the United States that enroll students from kindergarten/pre-K (age 5) through 8 th grade (up to age 14), combining the typical elementary school (K-5) and junior high or middle school (6-7-8).
} 
At this point, in the last decades, Educational Games have been used in many teaching contexts of different topics as: Business, Geography, History, and others (Connolly et al. 2012), as well as studied in different perspectives as violence (Anderson and Gentile 2014), learning (Linehan et al. 2014), playfulness (Scoresby and Shelton 2011), and others.

According to recent studies, a series of empirical results related to games-based learning has shown that despite the overwhelming publicity given to the negative impact of games, like most technologies before them, computer games can have both positive and negative impacts (Connolly et al. 2012). These results are important to demonstrate not only the efficacy of games in educational context, but also to highlight the importance of new studies in different kinds of Educational Games.

\subsection{Educational Games Virtualization}

In the contemporary world, the idea of 'virtualization' is considered and studied by philosophy, psychology, physics, biotechnology, arts, and others (Kerimbayev 2015), increasing topics related to virtualization in different contexts as social life, industry and education. In this perspective, Educational Games Virtualization is a process to create digital versions for traditional/physical Educational Games before used to teaching of a determined topic. The main goals of Educational Games Virtualization are keep/ preserve pedagogical and psychological aspects of the traditional/physical version of the educational games version and combine these aspects with the contemporary game design elements, in order to increase students' learning.

Educational Games Virtualization can be used in different contexts and be support in different educational topics. According to Oliveira and Silva Junior (2015), the Educational Games Virtualization process should be start with the choice of the traditional educational game and end with the process of game evaluation, in order to identify if the educational game (in the digital version) keeps/ preserves the pedagogical and psychological aspects from traditional/physical game version, as well identify if the game can be increase students' learning.

According to Santos et al. (2013) and Santos et al. (2015) this process involves a multidisciplinary team, with professionals from Computer Science (especially HumanComputer Interaction (HCI)), Pedagogy, Psychology and those from specific educational games application fields, for instance Mathematic, Language, Biology, and others, in order to auxiliary the Educational Game Virtualization process.

\subsection{Related Works}

In the last years, several studies have been done in order to develop and evaluate Educational Games based in the Educational Games Virtualization process. Generally, these studies are conducted in the context of mathematics education and aim to implement games capable to contribute to students' learning in elementary school and high school.

Given the background, Santos et al. (2013) proposed a process of Virtualize Educational Games used in previous decades to teach mathematical concepts. With this proposal, authors summarize the importance of keeping pedagogical and psychological concepts of traditional/physical game version, as well as associate these concepts to 
contemporary digital game elements. In this context, a series of performed studies aim to implement/virtualize Educational Games based on this process.

Togni et al. (2009) presented an Educational Game to mathematics teaching in elementary schools that was developed based in the Meaningful Learning Theory, and used with students in real context. However, they do not present concerns related to Computational and Pedagogical evaluation. Thusly, a similar work by Togni et al. (2009), Zorzal et al. (2008) showed a series of Educational Games virtualized using Augmented Reality (AR) resources, but do not presented concerns related to pedagogical and psychological aspects of games.

Recently, aiming to supply problems that were showed before, Santos et al. (2015) and Oliveira e Silva Junior (2015) proposed two Educational Games for mathematics teaching (called "Conquering with the Rest" and "Challenge with Sticks") developed based on the Educational Games Virtualization. These works were developed in the Elementary School context and were evaluated with students and teachers.

The studies showed before do not presented concerns related to specific methodologies of game virtualization and game evaluation, as well as do not presented concerns related to pedagogical and psychological concepts maintenance and do not presented concerns related to the influences of the game in the students' learning. Both studies before mentioned focused in mathematics teaching domain. The studies before showed contribute and reaffirm the importance of the challenges proposed in this paper.

\section{Challenges of Virtualization Game in Educational Games}

This section aims to present five challenges for Games Virtualization applied to Educational Games, however, some challenges also can be considered in the general Educational Games field. Figure 1 synthetize the challenges proposed, starting in the concept of Educational Game Virtualization.

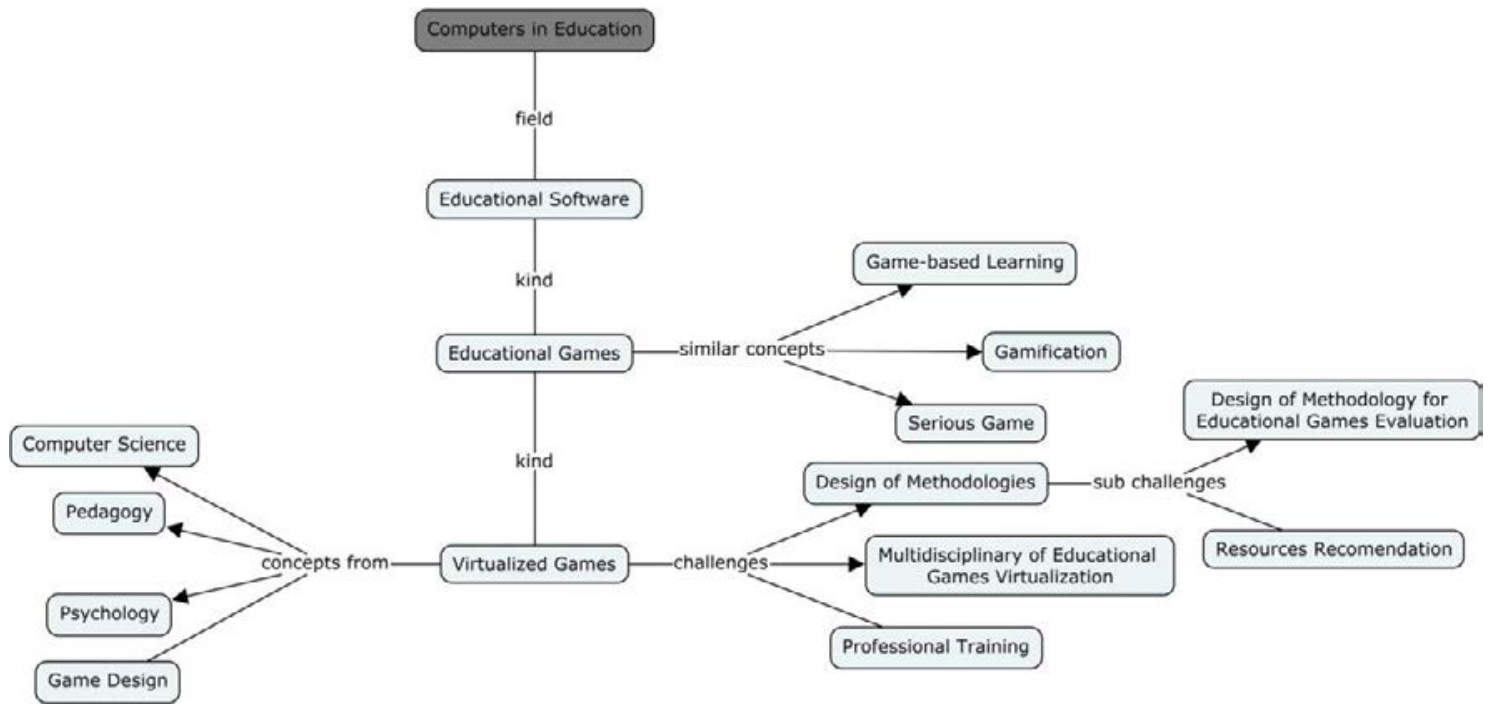

Figure 1: Conceptual map of challenges of Educational Games Virtualization 


\subsection{Challenge 1: Design of Methodologies for Educational Games Virtualization}

In the last years, some studies have been made addressing Educational Games Design based on Games Virtualization (e.g. Santos et al. (2014) and Oliveira e Silva Junior (2015)). However, these studies present different methodologies and process for the development of games, or use others methodologies from traditional game design. On the other hand, Educational Games Virtualization, different from conventional Games Development, as well as the conventional Educational Games Development, use concepts from different fields as Pedagogy, Psychology, Computer Science and others domains related to the context of game application.

On this subject, we propose, as a big challenge for Games Virtualization applied to Educational Games, the development of methodologies for Educational Games Virtualization. Considering that the Virtualization of Educational Games uses several concepts regarding Pedagogy, Psychology and Computer Science (as well as specifically concepts of the area of game application, for instance: Mathematic, Geography, Biology and others), is important that the methodologies consider some steps, starting with the traditional game chosen in partnership with professionals of application area, and ending with the game evaluation in real scenario, with students and partnership with professionals of application area, in order to evaluate if the game maintain pedagogical and psychological concepts from the traditional game, as well as if contributes to students' learning.

Based on the challenge proposed, we present some directions for researchers and professionals: $(i)$ design of methodologies to fill this gap, must be implemented with multidisciplinary teem and collaboration of professionals of Game Design, Computer Science, Psychology and Pedagogy, in order to aggregate different knowledge areas and implement a methodology with potential scientific and industrial; (ii) methodologies hereafter proposed must be evaluated by different professionals in different academicals and industrial scenarios to develop a methodology able to be used in both contexts; (iii) methodologies hereafter proposed should provide resources to virtualize Educational Games for different courses, not being addressed to specifically contexts.

\subsubsection{Challenge 1.1: Design of Methodologies for Educational Game Evaluation}

Recently, some studies have been done aiming to propose methodologies to Educational Games evaluation, for instance: Rocha and Araújo (2015) proposed an interactive methodology and integrative modes to develop serious games, integrating a holistic and multidisciplinary approach into the areas of simulation, game, learning, training and domain. This same study proposes a evaluate games model that is produced based in this methodology. From the basis, Barbosa et al. (2015) proposed a heuristic to Educational Games evaluation. Barbosa's methodology was based in a study with a series of existing heuristics, such as HEP, PLAY and GameFlow, and the Criteria for Designing Educational Computer Games from Nicola Whitton.

However, these methodologies and others similar methodologies (e.g. Medeiros (2015) and França e Silva (2014)) are focused in specifics fields, without elements with allowed use in different contexts, or yet, focus only in the game interface evaluation, in detriment of pedagogical elements, or focus only in pedagogical elements, 
in detriment of game interface, hindering apply these methodologies in Educational Games developed based on the Games Virtualization. In order to propose a solution for the gap that was talked before, Santos et al. (2015) proposed a qualitative and quantitative approach to the interface and pedagogical evaluation in Educational Games, including Educational Games developed based on Game Virtualization. However, this approach do not presents concerns related with specifics points of Educational Virtualization Games, as the maintenance of Pedagogical and Psychological principles of traditional games.

In this context, we propose, as a big challenge for Games Virtualization applied to Educational Games, design of methodologies to Educational Games evaluation developed based on Games Virtualization. So, as the Games Virtualization has the goal of keeping the pedagogical and psychological concepts of the traditional game, as well as associate these concepts contemporary elements of game design, future methodologies proposals to evaluate the games developed by the virtualization process games should be able to identify whether the pedagogical and psychological aspects of the traditional game are actually kept in the digital game. Since also Educational Game Virtualization is a computational process to solve educational problems, future methodologies proposed must be able to evaluate interface concepts used in the game, as well as evaluate if the game contributes to students' learning.

Based on the challenge before proposed, we present some directions to researchers and professionals: $(i)$ methodologies hereafter proposed should develop with professionals of different domains as: Pedagogy, Psychology and Computer Science (especially Software Engineering and $\mathrm{HCI}$ ), in order to provide a methodology capable to evaluate games according to different criteria, from Pedagogy, Psychology and Computer Science (HCI); (ii) methodologies hereafter proposed should provide minimally the following resources: evaluate if the game keeps the Pedagogical and Psychological principles allied to contemporary game design elements, evaluate the game quantitatively and qualitatively in aspects of Computers Science (specially HCI) and Pedagogical aspects, as well as evaluate if the game contributes to students' learning.

\subsubsection{Challenge 1.2: Recommendation of Resources for Educational Games Virtualization}

In the last decades, with technology advent in several society contexts, a series of new technologies in the software development industry have been daily emerged. A series of new programming languages, tools, engines and others general resources emerged too. According to Ampatzoglou and Stamelos (2010), similar it happens in the industry of games that has a series of specifics programming languages, tools and general engines. In the Educational Games industry, this situation is highlighted because professionals need integration between technical and pedagogical contexts (Chaudy et al. 2014). On the other hand, few studies have been done to help professionals of educational game design.

In this regard, we propose, as a big challenge for Virtualization Game applied to Educational Game, recommendation of resources to Educational Games Virtualization process. This challenge refers to development of studies in order to 
identify programming languages, tools, engines and general resources capable to help professionals of Educational Game Design to develop Educational Games based on the Educational Game Virtualization, this challenge is not an exclusive challenge on Educational Games Virtualization, but is a challenge that comprises all Educational Games development field.

Based on the challenge before proposed, we present some directions to researchers and professionals: $(i)$ future studies aiming to identify programming languages, tools, engines and general resources should be developed with empirical metrics in order to provide resources to futures replications in different contexts; (ii) studies hereafter conducted to identify resources to development of Educational Games based in Virtualization Games should be developed with partnerships professionals of Science Computers and Education, in order to recommend resources capable to facilitate the process of development and maintenance of Educational Games (integration between technical and educational concepts).

\subsection{Challenge 2: Multidisciplinary of Educative Games Virtualization}

Recently, a series of studies addressing Educational Games Virtualization have been done. However, majority of studies have been carried out to Mathematic domain, especially considering studies before presented (see Related Works). On the other hand, considering the concept of Game Virtualization, many others domains use/used traditional games in classroom to increase students' learning in several activities, as well as to improve the involvement of the students, in domains for instance: Biology, Geography, Literature, and others (Connolly et al. 2012).

In this context, we propose, as a big challenge for Games Virtualization Applied to Educational Games, multidisciplinary development of educational games, based on Games Virtualization. Considering the majority studies in Educational Games Virtualization being developed in the context of Mathematic course, is recommended the development of others games in others domains, in order to evaluate the efficacy of Educational Game Virtualization in different contexts, as well as identify games' consequences in students in different situations and contexts.

Based on the challenge proposed before, we present some directions to researchers and professionals: (i) games hereafter virtualized should be developed and evaluated according to specifics methodologies of Educational Game Virtualization, in order to permit a robust evaluation in Computational and Pedagogical aspects, as well as permit future applications of works; ( $i i)$ game hereafter virtualized should be evaluated in different real contexts (with real classroom and real students).

\subsection{Challenge 3: Professional Training to Educational Games Virtualization}

Professional training has become a big challenge in the industry and education in the last years. In the past few years, various studies have been conducted to provide professional training resources in different domains (e.g. Rocha and Araújo (2015) and Gurinović et al. (2015)). In the game industry, it is no different, faced with a series of tools updates, devices, clients, among others, the industry of game design undergoes constant changes and need to invest a high value on training professionals, in order to maintain your competitiveness. 
In the Educational Game industry also is no different, starting with the updates before showed, as well as increasing specifics points, for instance: multidisciplinary team, different evaluation process, integration with educational context, and others. Educational Game industry suffered even more with this updates and was necessary to invest annual big amounts with training of professionals. Thusly, we propose as a big challenge for Game Virtualization applied to Educational Games, professional training to Educational Games Virtualization.

Based on the challenge before proposed, we present some directions to researchers and professionals: $(i)$ before the importance of professionals to development of educational resources, we consider necessary invest in the professional multidisciplinary capacitation and specialization, in order to form professionals capable to deal with different situations (in the industry and academy), as well as they will be able to deal with the integration of technology (game design approach), and education; (ii) futures research groups, companies and others professional groups interested in Educational Games Virtualization can invest in the integration academy-industry, in order to training professionals capable to deal with these different scenarios.

\section{Concluding Remarks}

In the past few years, Educational Game Virtualization have been addressed as a promising topic of Educational Game, especially to provide to students, pedagogical and psychological aspects of traditional/physical games, allied to modern game design approaches (e.g. Santos et al. (2015) and Oliveira and Silva Junior (2015)). However, before a series of studies recently conducted in Educational Virtualization Games, a series of challenges have been appeared. In this way, this paper proposed and discussed addressed a series of big challenges for the Game Virtualization applied to Educational Game Virtualization.

This paper proposed and discussed a series of challenges for Virtualization Games applied to Educational Games: ( $i$ ) Design of methodologies for educational games virtualization, (i.i) design of methodologies for educational game evaluation, (i.ii) recommendation of resources for Educational Games Virtualization, (ii) multidisciplinary of Educational Games Virtualization, and (iii) professional training to Educational Games Virtualization.

Finally, as general recommendations, we highlight the importance of methodologies design to Educational Games development and evaluation, of educational games developed based on the process of Educational Games Virtualization, as well as the importance of evaluate these games in real and different contexts and invest in the training of professional to development of Educational Games based in the Educational Games Virtualization. Finally, as future work, we highlight the execution of State of the Art and Systematic Literature Review in order to obtain a general empirical overview in this field, as well as studies in order to propose specifically methodologies to Educational Games Virtualization.

\section{References}

Ampatzoglou, A., \& Stamelos, I. (2010). Software engineering research for computer games: A systematic review. Information and Software Technology, 52(9), 888-901. 
Anderson, C. A., \& Gentile, D. A. (2014). Violent Video Game effects on Aggressive thoughts, feelings, physiology, and Behavior. Media Violence and Children: A Complete Guide for Parents and Professionals, 229.

Anderson, C. A., Shibuya, A., Ihori, N., Swing, E. L., Bushman, B. J., Sakamoto, A., \& Saleem, M. (2010). Violent video game effects on aggression, empathy, and prosocial behavior in eastern and western countries: a meta-analytic review. Psychological bulletin, 136(2), 151.

Babosa, M. B., Rêgo, A. B., \& Medeiros, I. (2015). HEEG: Heuristic Evaluation for Educational Games. In: XIV Brazilian Symposium of Games and Digital Entertainment. Teresina-PI, Brazil.

Chaudy, Y., Connolly, T. M., \& Hainey, T. (2014). EngAGe: A link between Educational Games Developers and Educators. In: Games and Virtual Worlds for Serious Applications (VS-GAMES), 2014 6th International Conference on (pp. 1-7). IEEE.

Connolly, T. M., Boyle, E. A., MacArthur, E., Hainey, T., \& Boyle, J. M. (2012). A systematic literature review of empirical evidence on computer games and serious games. Computers \& Education, 59(2), 661-686.

Essential facts about the computer and video game industry: 2015 sales, demographic and usage data. Entertainment Software Association, 2015.

França, R. S., \& Silva, A. C. B. (2014). Avaliação de softwares educativos para o ensino de Língua Portuguesa. Revista Brasileira de Informática na Educação, 22(03), 23.

Gurinović, M., Novaković, R., Šatalić, Z., Nikolić, M., Milešević, J., Ranić, M., \& Glibetić, M. (2015). Professional training in nutrition in Central and Eastern Europe: current status and opportunities for capacity development. Public health nutrition, 18(02), 372-377.

Kerimbayev, N. (2015). Virtual learning: Possibilities and realization. Education and Information Technologies, 1-13.

Linehan, C., Bellord, G., Kirman, B., Morford, Z. H., \& Roche, B. (2014). Learning curves: analysing pace and challenge in four successful puzzle games. In Proceedings of the first ACM SIGCHI annual symposium on Computer-human interaction in play (pp. 181-190). ACM.

Lofgren, K. (2015) Video Game Statistics \& Trends Who's Playing What \& Why?. Available in: http://www.bigfishgames.com/blog/2015-global-video-game-statswhos-playing-what-and-why/. Accessed: 09/March/2016.

Medeiros, J. F. (2015) Avaliação de Usabilidade e Jogabilidade: Métodos, Técnicas e Ferramentas. In: XIV Simpósio Brasileiro de Jogos e Entretenimento Digital. Teresina-PI, Brasil.

Oliveira, W., Neto, S., da Silva Junior, C. G., \& Bittencourt, I. I. (2015). Avaliação de Jogos Educativos: Uma Abordagem no Ensino de Matemática. In: Anais do Simpósio Brasileiro de Informática na Educação (Vol. 26, No. 1, p. 657). 
Oliveira, W., \& da Silva Junior, C. G. (2015). Pesquisa, Desenvolvimento e Avaliação de um Jogo para o Ensino de Matemática, Baseado no Processo de Virtualização de Jogos. In Anais dos Workshops do Congresso Brasileiro de Informática na Educação (Vol. 4, No. 1, p. 145).

Rocha, R. (2015). Metodologia iterativa e modelos integradores para desenvolvimento de jogos sérios de treinamento e avaliação de desempenho humano. In Anais dos Workshops do Congresso Brasileiro de Informática na Educação (Vol. 4, No. 1, p. 13).

Santos, W., Silva Neto, S. R., \& Silva Junior, C. G. (2013). Uso de Games no ensino da Matemática. Uma proposta de virtualização dos jogos tradicionais, para uso como mecanismo de apoio ao processo de ensino e aprendizagem. In: Anais do Simpósio Hipertexto e Tecnologias na Educação, Recife-PE.

Santos, W., O.; Souza, A., A.; da Silva, A., K., T.; Oliveira, M., L., S.; Silva Neto, S., R.; Rodrigues, A. N., Silva Junior, C. G. (2015) Development Process of an Educational Game: An experience in Brazil. In: XIV Brazilian Symposium of Games and Digital Entertainment. Teresina-PI, Brazil.

Scoresby, J., \& Shelton, B. E. (2011). Visual perspectives within educational computer games: effects on presence and flow within virtual immersive learning environments. Instructional Science, 39(3), 227-254.

Rocha, R., \& Araújo, R. B. (2015). Metodologia iterativa e modelos integradores para desenvolvimento de jogos sérios de treinamento e avaliação de desempenho humano. In: Anais dos Workshops do Congresso Brasileiro de Informática na Educação (Vol. 4, No. 1, p. 13).

Scoresby, J., \& Shelton, B. E. (2011). Visual perspectives within educational computer games: effects on presence and flow within virtual immersive learning environments. Instructional Science, 39(3), 227-254.

Silva Neto, S. R., Santos, H. R., Souza A. A., Santos W. O. (2013) Jogos Educacionais como Ferramenta de Auxílio em Sala de Aula. In: Anais do Workshop de Informática na Escola (Vol. 1, No. 1, p. 130).

Togni, A. C., Rehfeldt, M. J. H., Bersch, M. E., Thomas, M. I. P., Poletti, C. F., \& Kronbauer, K. A. (2009). Piff geométrico: um objeto virtual de aprendizagem para o ensino de ciências exatas. RENOTE, 7(3), 45-52.

Webster, D., \& Celik, O. (2014). Systematic review of Kinect applications in elderly care and stroke rehabilitation. Journal of neuroengineering and rehabilitation, 11(1), 1.

Zorzal, E. R., Kirner, C., Cardoso, A., Lamounier Jr, E., de Oliveira, M. R. F., \& Silva, L. F. (2008). Ambientes Educacionais Colaborativos com Realidade Aumentada. RENOTE, 6(2). 